\title{
A High-Integration On-Chip Reconfigurable Monopole
}

\author{
Han $\mathrm{Su}^{1 \mathrm{a})}$
}

Abstract In this paper, a silicon-based high-integration frequency reconfigurable monopole is designed. This antenna is designed on silicon wafer, and all manufacturing steps are completely compatible with silicon process. This method can integrate silicon-based antenna into communication system easily. To further improve the antenna's integration, an optimized band stop filter is introduced into the antenna system to replace the conventional capacitor and inductor, and measurement results confirm the usefulness of this filter. Based on these results, the designed monopole achieved two frequency configurations at $3.23 \mathrm{GHz}$ and $4.48 \mathrm{GHz}$, and other radiation parameters are also shown good results.

key words: frequency reconfigurable monopole, high integration, band stop filter

Classification: Microwave and millimeter wave devices, circuits, and hardware

\section{Introduction}

Nowadays, with the rapid development of wireless communications, the conventional antenna system which realized a single radiation performance can't satisfy the requirements of communications [1-5]. To improve the integration of antenna system and reduce the system complexity, frequency reconfigurable antennas which have different standards or multi-frequency applications within a single antenna system have been attracting more and more attentions of many researchers. There are several switching elements (PIN diodes, MEMS, or varactor) within the antenna system to realize the antenna's reconfigurability. When changing the active length or the current distribution of the antenna, the resonant frequency will shift to another configuration [69]. To meet the requirements of modern communication, antenna systems today have been developing toward the direction of miniaturization and automation. The traditional antennas were fabricated on PCB and other materials, and it was hard to integrate into silicon systems. Besides, the traditional antennas were powered through dc bias lines, and several capacitors and inductors were placed in these lines to provide enough

\footnotetext{
${ }^{1}$ College of Information Engineering, Engineering University of PAP, Xi'an 710086, China

a) suhanlq@163.com
}

DOI: $10.1587 /$ elex.18.20210462

Received November 04, 2021

Accepted December 13, 2021

Publicized December 22, 2021 isolation of the AC signals. Restricted by its sizes, these antennas were hard to realize high integration and miniaturization [10-17]. Therefore, a silicon-based reconfigurable monopole antenna based on band stop filters is investigated in this paper to solve this problem. This silicon-based frequency reconfigurable monopole is fabricated on silicon wafer, and all manufacturing steps are completely compatible with silicon process. A high resistivity silicon substrate is used to fabricate this antenna as a substrate, and it has good temperature and mechanical properties. Compared with the traditional antenna, this antenna is more suitable for working at higher frequencies. Besides, this silicon-based antenna can also be used in other wireless systems, such as satellite communication, radar, smartphone chips, and intelligent home systems, etc [18-22]. Investigation of silicon-based solid state plasma reconfigurable antennas with surface PiN diodes is another reason to use silicon substrate. These antennas were characterized by its wideband frequency range, good stealth characteristic, and dynamic reconfigurability, which have broad application prospects in the future.

In the traditional antenna system, several capacitors and inductors were predefined into the feeding networks to provide isolation between the feeding lines and the antenna radiator, and these devices will greatly reduce the system integration [23-26]. To further improve the integration of antenna system, an optimized band stop filter is introduced to isolate the AC signals. The size of this filter is designed according to the operating frequency of the reconfigurable monopole, and it can be designed together with the monopole within a single silicon system. Therefore, these high integrated antennas with band stop filters are more suitable for modern communication systems [27-31].

The operating principle and structure model of the monopole antenna are discussed in section 2. Simulated and measured results of this high integration reconfigurable monopole are shown in section 3 . Conclusion is given in section 4 .

\section{Analysis and design of the monopole}

As illustrated in Fig. 1, the proposed frequency reconfigurable monopole antenna mainly consists of an antenna radiator, three band stop filters (A1, A2, and A3), 
coaxial line, ground plane, and silicon wafer. This antenna is designed on a square silicon wafer (the relative permittivity $=11.8$, the conductivity $=3 \mathrm{~S} / \mathrm{m}$, the loss tangent $=0.01$, the thickness $=450 \mu \mathrm{m}$ ), and the monopole conductor and band stop filters are aluminum with a thickness of $2 \mu \mathrm{m}$. The monopole radiator and ground plane are connected by several optimized band stop filters, and the required $\mathrm{AC}$ signal is applied on the monopole antenna through the coaxial line. The monopole's reconfigurability is realized by turning on or off different filters. The Ansoft High Frequency Structure Simulator (HFSS) is used to optimize the structural parameters of this antenna.

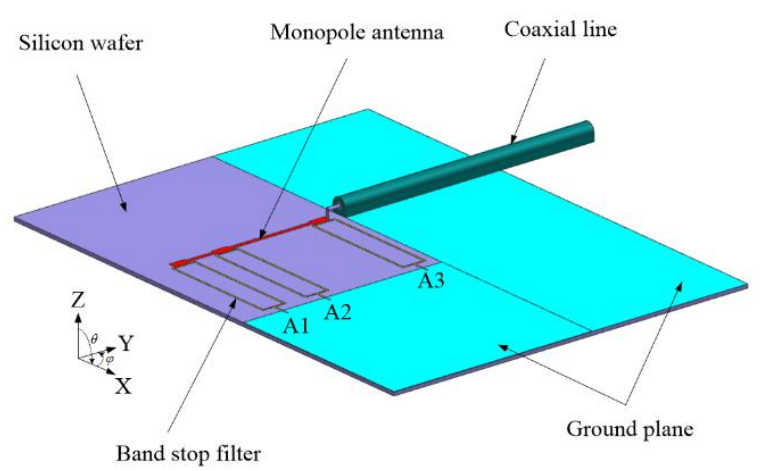

Fig. 1 Structural schematic diagram of the monopole antenna.

The monopole radiator's size is designed according to the wavelength at the centre frequency, and the total length of the monopole conductor is $20 \mathrm{~mm}$ in this paper. From Fig. 1, this monopole is divided into two parts by the band stop filters, and the monopole's reconfigurability can be demonstrated by turning different sections on or off to change the active length of the radiator. As expected, as more sections are turned on, the resonant frequency shifts to lower values [13-16]. Table I shows two different working states of the reconfigurable monopole antenna. Other combinations of these filters are not discussed in this paper. When A1 and A3 are turned on, this monopole is working in the low frequency mode. In correspondence with it, high frequency mode is carried out when A2 and A3 are turned on. Other resonant frequencies can also be achieved by changing the positions of the band stop filters, and the designed frequencies in this paper are demonstrated for the antenna's working mechanism.

Table 1 Two states of the monopole.

\begin{tabular}{clll}
\hline Band stop filter & A1 & A2 & A3 \\
\hline State 1 & ON & OFF & ON \\
\hline State 2 & OFF & ON & ON \\
\hline
\end{tabular}

\section{Simulated and measured performances}

The frequency reconfigurable monopole with band stop filters is fabricated and measured, and Fig. 5 exhibits the photograph of this monopole. The feeding network is fabricated on microwave composite dielectric substrate TP-2 (the relative permittivity $=9.8$, the loss tangent $=$ $1 \times 10^{-4}$, the thickness $=0.4 \mathrm{~mm}$ ) to feed the monopole antenna, and all test steps are carried out on room temperature. The feeding network in Fig. 5 (a) is just dc bias lines to power the antenna system through the band stop filters, and it has little effect on antenna's performance.

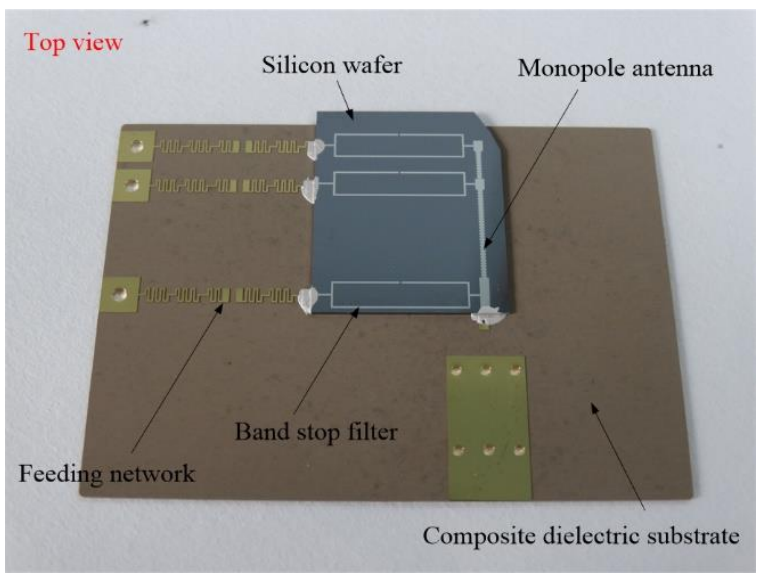

(a)

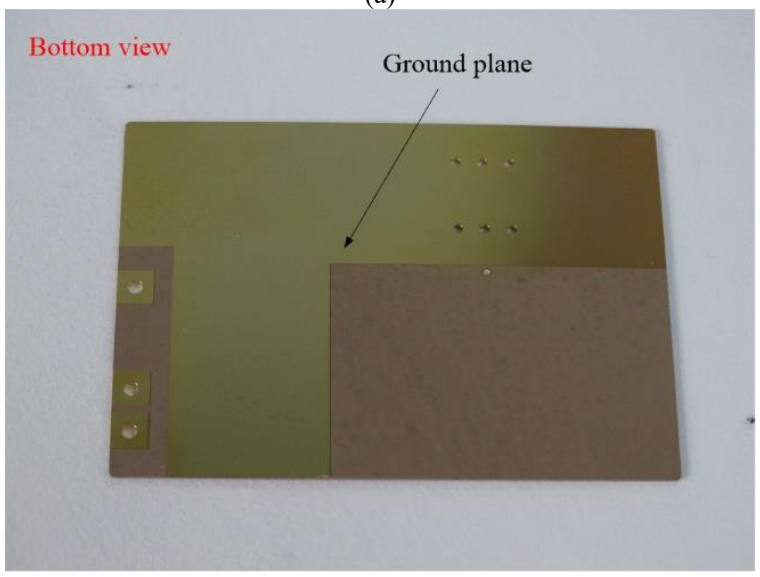

(b)

Fig. 2 Prototype photos of the proposed monopole, (a) top view, (b) bottom view.

Comparison of the simulated and measured S11 at two configurations are shown in Fig. 6. The results indicated that the $\mathrm{S} 11$ of the reconfigurable monopole antenna smaller than $-10 \mathrm{~dB}$ were approximately $2.5 \mathrm{GHz}-3.5$ $\mathrm{GHz}$ and $4.1 \mathrm{GHz}-4.8 \mathrm{GHz}$, respectively. Besides, from this figure it can be concluded that with different working states the monopole antenna resonates at different frequencies, and the monopole antenna realized two resonant frequencies at $3.23 \mathrm{GHz}$ and $4.48 \mathrm{GHz}$ when changing the active length of the radiator. The 
difference between the simulated and measured results may be caused by using silicon wafer, band stop filters, microwave composite dielectric substrate TP-2, and conductive silver paste.

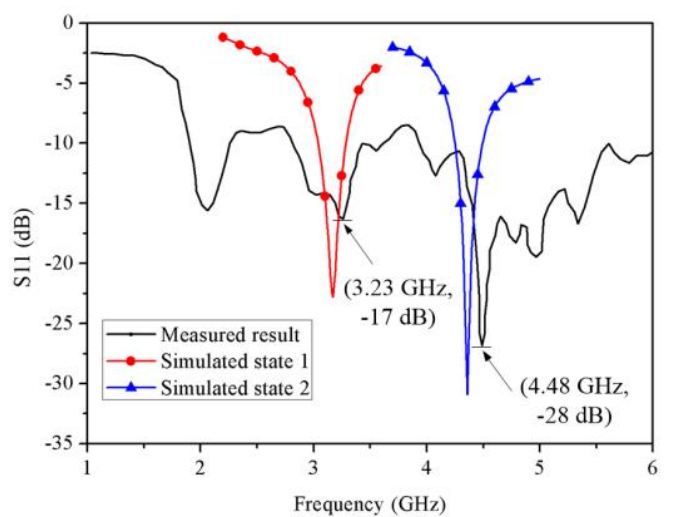

Fig. 3 Measured and simulated S11 of the proposed monopole.

The radiation patterns of the frequency reconfigurable monopole antenna are also measured in an anechoic chamber, and the simulated and measured radiation patterns of the reconfigurable monopole at different working states are presented in Fig. 7, respectively. It can be concluded that the monopole antenna obtained a maximum gain of $2.1 \mathrm{~dB}$, and the values of gain are very close in both cases. The disagreement between measured and simulated results may be caused by using other dielectric materials, and this proposed monopole has good radiation characteristics.

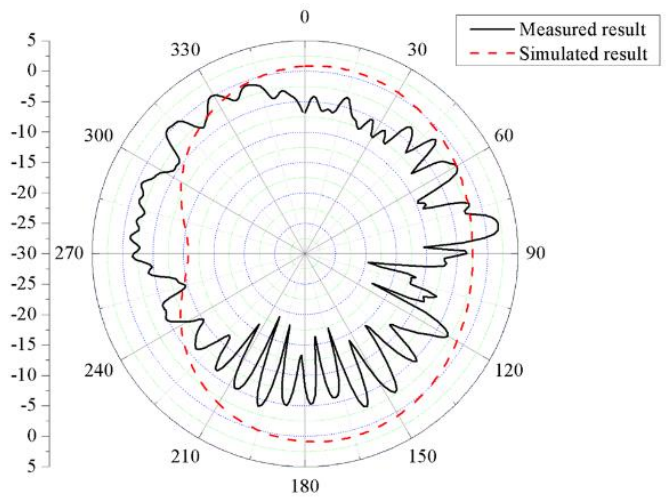

(a)

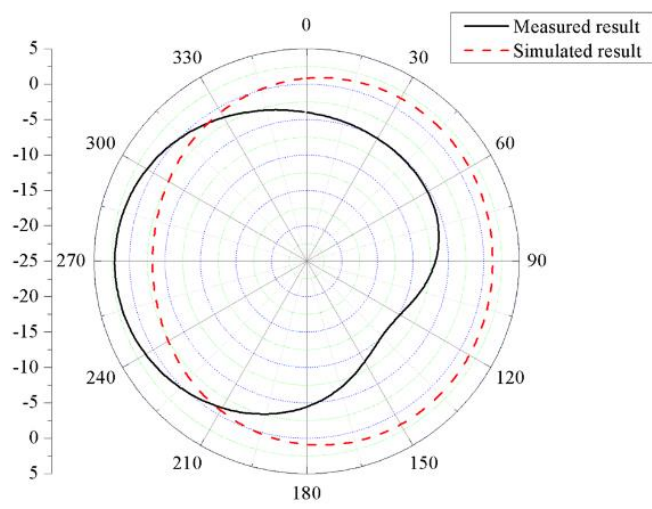

(b)

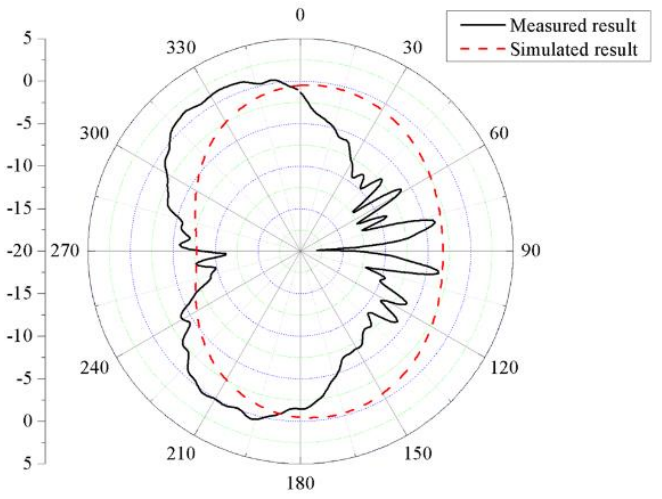

(c)

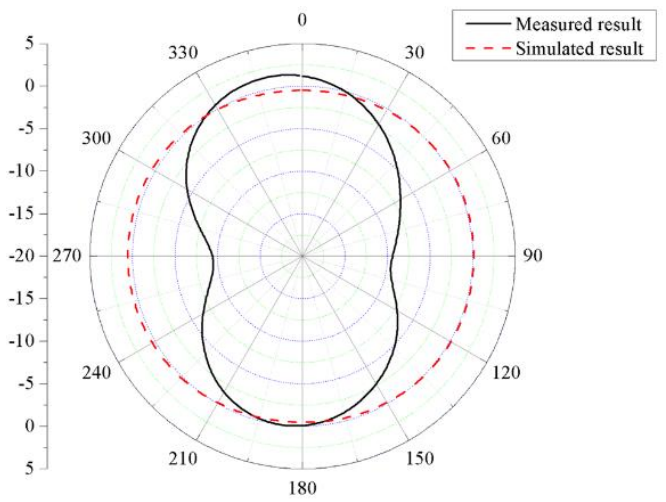

(d)

Fig. 4 Measured and simulated radiation patterns for antenna prototype (a) E plane at $3.23 \mathrm{GHz}$ (b) $\mathrm{H}$ plane at $3.23 \mathrm{GHz}$ (c) E plane at 4.48 $\mathrm{GHz}$ (d) $\mathrm{H}$ plane at $4.48 \mathrm{GHz}$.

To further investigate the mechanism of the monopole antenna, it is imperative to analyse the current distributions and electric field distributions of the reconfigurable monopole at different working states. The simulated current and electric field distributions of the reconfigurable antenna are shown in Fig. 8. Furthermore, the radiation efficiencies of the reconfigurable monopole at two configurations are $70.8 \%$ and $65.7 \%$, respectively. 


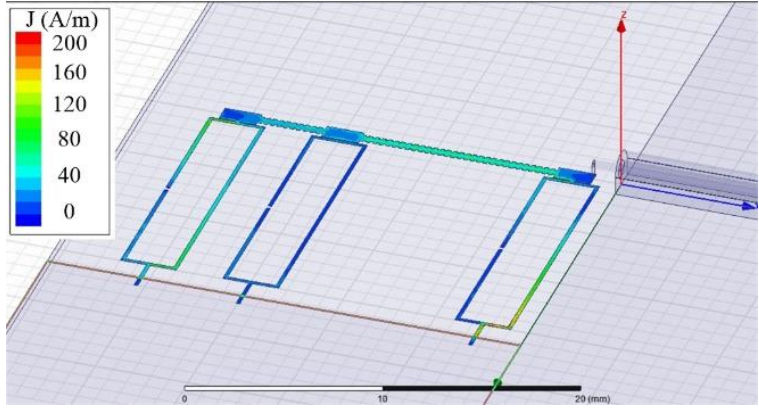

(a)

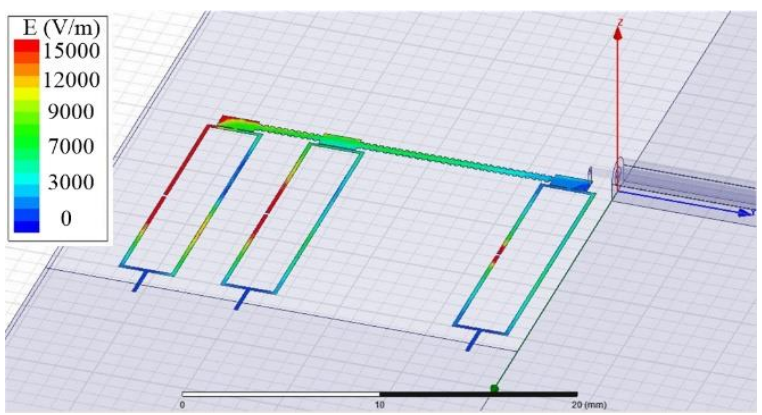

(b)

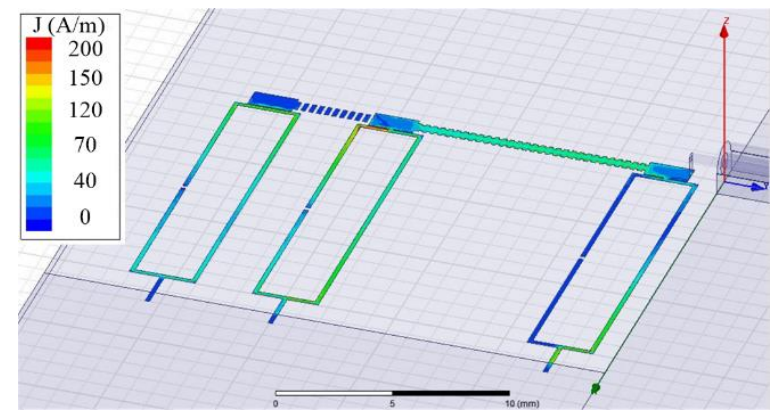

(c)

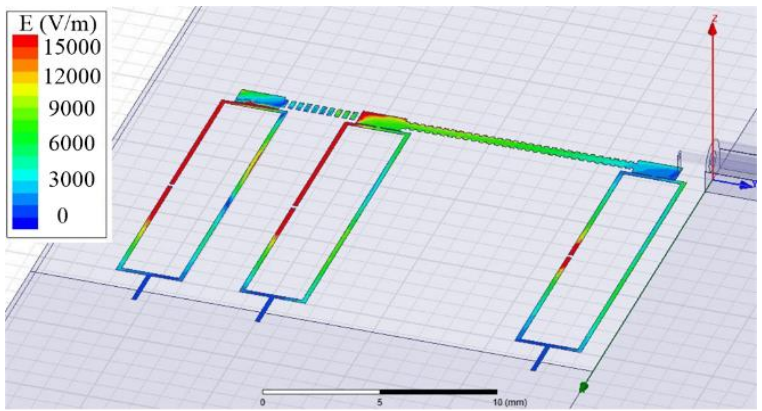

(d)

Fig. 5 Simulated current distributions and electric field distributions of the reconfigurable monopole (a) current distribution at $3.23 \mathrm{GHz}$ (b) electric field distribution at $3.23 \mathrm{GHz}$ (c) current distribution at 4.48 $\mathrm{GHz}(d)$ electric field distribution at $4.48 \mathrm{GHz}$.

\section{Conclusion}

This paper presents the experimental demonstration of silicon-based high integration reconfigurable monopole antenna. This antenna is designed on silicon wafer, and several optimized band stop filters are introduced into antenna system to improve antenna's integration. Based on the previous results, this reconfigurable antenna achieved good radiation characteristics, and two configurations at $3.23 \mathrm{GHz}$ and $4.48 \mathrm{GHz}$ are also demonstrated. Besides, the reconfigurable monopole antenna obtained a maximum gain of $2.1 \mathrm{~dB}$ at both configurations, and the radiation efficiencies at two configurations are $70.8 \%$ and $65.7 \%$, respectively. Power loss and semiconductor process should be further research in the future work.

\section{Acknowledgments}

This work was supported by Scientific Research Innovation Team of Engineering University of PAP named as "The theory and its application of PAP C4ISR" (No. KYTD201803).

\section{References}

[1] N.H. Chamok, et al.: "High-Gain Pattern Reconfigurable MIMO Antenna Array for Wireless Handheld Terminals," IEEE Trans. Antennas Propagat. 64 (2016) 4306 (DOI: 10.1109/TAP.2016.2598201).

[2] J. S. Row and J. F. Tsai: "Frequency reconfigurable microstrip patch antennas with circular polarization," IEEE Antennas Wireless Propag. Lett. 13 (2014) 1112 (DOI: 10.1109/LAWP.2014.2330293).

[3] X. J. Sheng, et al.: "Design of frequency selective rasorber with high in-band transmission and wideband absorption properties," IEICE Electron. Express $16 \quad$ (2019) 20190545 (DOI: 10.1587/elex.16.20190545).

[4] H. A. Majid, et al.: "Frequency and pattern reconfigurable slot antenna," IEEE Trans. Antennas Propag. 62 (2014) 5339 (DOI: 10.1109/TAP.2014.2342237).

[5] N.A Bishop, et al.: "A Broadband High-Gain Bi-Layer LPDA for UHF Conformal Load-Bearing Antenna Structures (CLASs) Applications," IEEE Trans. Antennas Propagat. 63 (2015) 2359 (DOI: 10.1109/TAP.2015.2409866).

[6] A. Mehdipour, et al.: "Reconfigurable TX/RX antenna systems loaded by anisotropic conductive carbon-fiber composite materials," IEEE Trans. Antennas Propag. 62 (2014) 1002 (DOI: 10.1109/TAP.2013.2293784).

[7] N. Liu, et al.: "A feasible bandwidth compensation technique for FSS radome design," IEICE Electron. Express 14 (2017) 20170510 (DOI: 10.1587/elex.14.20170510).

[8] J. Costantine, et al.: "Analyzing the complexity and reliability of switch frequency reconfigurable antennas using graph models," IEEE Trans. Antennas Propag. 60 (2012) 811 (DOI: 10.1109/TAP.2011.2173104).

[9] L.N. Pringle, et al.: "A Reconfigurable Aperture Antenna Based on Switched Links Between Electrically Small Metallic Patches," IEEE Trans. Antennas Propag. 52 (2004) 1434 (DOI: 10.1109/TAP.2004.825648).

[10] S. Soltani, et al.: "A port and frequency reconfigurable MIMO slot antenna for WLAN applications," IEEE Trans. Antennas Propag. 64 (2016) 1209 (DOI: 10.1109/TAP.2016.2522470).

[11] Y. Tawk, et al.: "Integrated wide-narrowband antenna for multistandard radio," IEEE Trans. Antennas Propag. 59 (2011) 1773 (DOI: 10.1109/TAP.2011.2152353).

[12] D. Titz, et al.: "Development of a millimeter-wave measurement setup and dedicated techniques to characterize the matching and 
radiation performance of probe-fed antennas," IEEE Antennas Propag. Mag. 54 (2012) 188 (DOI: 10.1109/MAP.2012.6309179).

[13] J. Liu, et al.: "Design and analysis of a low-profile and broadband microstrip monopolar patch antenna," IEEE Trans. Antennas Propag. 61 (2013) 11 (DOI: 10.1109/TAP.2012.2214996).

[14] A. Tennant and B. Chambers: "A single-layer tuneable microwave absorber using an active FSS," IEEE Microw. Wireless Compon. Lett. $14 \quad$ (2004) 46 (DOI:10.1109/LMWC.2003.820639).

[15] H. Rajagopalan, et al.: "MEMS reconfigurable optimized Eshaped patch antenna design for cognitive radio," IEEE Trans. Antennas Propag. 62 (2014) 1056 (DOI: 10.1109/TAP.2013.2292531).

[16] M. Li, et al.: "An ultrathin and broadband radar absorber using resistive FSS," IEEE Antennas Wireless Propag. Lett. 11 (2012) 748 (DOI: 10.1109/LAWP.2012.2206361).

[17] M. R. Chaharmir and J. Shaker: "Design of a multilayer X/Kaband frequency-selective surface-Backed reflectarray for satellite applications," IEEE Trans. Antennas Propag. 63 (2015) 1255 (DOI: 10.1109/TAP.2015.2389838).

[18] L. Wang, et al.: "A multifunctional frequency-selective polarization converter for broadband backward-scattering reduction," IEEE Trans. Antennas Propag. 69 (2021) 2833 (DOI: 10.1109/TAP.2020.3030966).

[19] D. Rodrigo and L. Jofre, "Frequency and radiation pattern reconfigurability of a multi-size pixel antenna," IEEE Trans. $\begin{array}{llllll}\text { Antennas } & \text { Propag. } & 60 & (2012) & 2219 & \text { (DOI: }\end{array}$ 10.1109/TAP.2012.2189739).

[20] M. S. Iqbal, et al.: "FSS inspired polarization insensitive chipless RFID tag,” IEICE Electron. Express 14 (2017) 20170243 (DOI: 10.1587/elex.14.20170243).

[21] A. T. Ho, et al.: "Circular ploarized square slot antenna based on slow-wave substarte integrated waveguide," IEEE Trans. Ant. Propag. 69 (2021) 1273 (DOI: 10.1109/TAP.2020.3030933).

[22] H. Jin H, et al.: "Miniaturized broadband coupler made of slowwave half-mode substrate integrated waveguide," IEEE Microw. Wireless Compon. Lett. 27 (2017) 132 (DOI: 10.1109/LMWC.2016.2646915).

[23] H. Jin, et al.: "Slow-wave half mode substrate integrated waveguide with partially polyline loading," IEICE Trans. Elec., E99-C (2016) 1323 (DOI: 10.1587/transele.E99.C.1323).

[24] H. Jin, et al.: "Slow-wave effect of substrate integrated waveguide patterned with microstrip polyline," IEEE Trans. Microw. Theory Techn. 64 (2016) 1717 (DOI: 10.1109/TMTT.2016.2559479).

[25] G. V. Eleftheriades, et al.: "Planar negative refractive index media using periodically L-C loaded transmission lines," IEEE Trans. Microw. Theory Techn. 50 (2002) 2702 (DOI: 10.1109/TMTT.2002.805197).

[26] N. Yang, et al.: "Broadband compact $180^{\circ}$ hybrid derived from the Wilkinson divider," IEEE Trans. Microw. Theory Techn. $\mathbf{5 8}$ (2010) 1030 (DOI: 10.1109/TMTT.2010.2042631).

[27] M. C. Scardelletti, et al:: "Miniaturized Wilkinson power dividers utilizing capacitive loading," IEEE Microwave and Wireless Components Letters 12 (2002) 6 (DOI: 10.1109/7260.975717).

[28] C. Bao, et al.: "An optimization algorithm in ultrawideband bandpass Wilkinson power divider for controllable equal-ripple level," IEEE Microwave and Wireless Components Letters (2020) 861 (DOI: 10.1109/LMWC.2020.3011516).

[29] X. Wang, et al.: "Synthesis theory of ultra-wideband bandpass transformer and its Wilkinson power divider application with perfect in-band reflection/isolation," IEEE Trans. Microw.
Techn.
67
(2019)

(DOI:10.1109/TMTT.2019.2918539).

[30] X. J. Sheng, et al.: "Design of frequency selective rasorber with high in-band transmission and wideband absorption properties," IEICE Electron. Express 16 (2019) 20190545 (DOI: 10.1587/elex.16.20190545).

[31] T. Deng, et al.: "Design of 3-D multilayer ferrite-loaded frequency selective rasorbers with wide absorption bands," IEEE Trans. Microw. Theory Techn. 67 (2019) 108 (DOI: 10.1109/TMTT.2018.2883060). 